\title{
MEASURING AND FORECASTING LOCAL ECONOMIC ACTIVITY: A STATUS REPORT
}

\author{
Claude Farrell and William W. Hall, Jr.*
}

\section{Introduction}

A survey was conducted over 1987-88 to obtain information on the extent to which regional economists were engaged in measuring and forecasting local economic activity. A total of 250 members of the Association for University Business and Economic Research and the Southern Regional Science Association were surveyed.

We anticipated that many individuals engaged in this activity would be identified. To our surprise, only 12.3 percent of the respondents were measuring and forecasting local economic activity. The comment most frequently provided by respondents was not directly solicited by the survey questions. Rather, it was a concern and request in response to the purpose of the survey. Approximately 60 percent of the respondents commented that they would like to be engaged in this activity. However, they indicated that they did not know how to do it, where to get started, or that the problems they perceived prevented them from doing it. Two typical comments were:

"We would love to be able to do this. (We) Have continuous requests from the public and private sector for this type of information. (We) Hope that your survey helps us get started."

"It is embarrassing to be at a large public institution (,) and no one has any answers to the focus of your survey. (I) Hope that your survey sheds some light."

In response to this interest, the focus of our reporting of the survey results and literature review shifted. The intended specific objectives of this paper are twofold. First, some of the tools which can be used to measure and forecast local economic activity will be presented. Second, some of the primary obstacles encountered in this pursuit will be discussed.

The survey results are briefly reported and used as the basis in meeting the intended objectives. The literature review at the end of this paper is also directed to this end.

-Professor of Economics and Associate Professor of Economics, respectively, The University of North Carolina at Wilmington.
A condensed copy of the survey instrument is attached as Appendix I. Overview Of Survey Results

There were 106 responses to the survey, an approximate 42 percent response rate. However, if those who responded that they were answering for more than one person who received the survey are included, the response rate was 58 percent. Responses were received from all 50 states and Canada. Table 1 summarizes these responses.

As previously pointed out, only a small percentage $(12.3+2.8=15.1)$ of the respondents were measuring overall local economic activity. A slightly larger percentage $(12.3+9.4=21.7)$ were forecasting overall local economic activity or separate data series. Over three-fourths ( 45.3 percent +30.2 percent $=75.5$ percent) were neither measuring nor forecasting overall local economic activity or separate data series. 54.7 percent were maintaining local data series.

\section{Measuring Overall Local Economic Activity Results}

Table 2 summarizes information provided by the 16 respondents who were measuring overall local economic activity.

Of the eight respondents using indexes, the most frequently cited technique, factor analysis was the only methodology reported. The most common variables used in the indexes were retail sales, employment, electricity usage, housing/construction, and a financial measure. Other variables in the indexes were quite varied, reflecting at times the specific nature of a region, e.g., tourism, port activity, and military expenditures. A measure of agricultural activity was included in only one index.

Only one large scale econometric model was reported. All others citing econometric models used multiple regression analysis with either income or employment as the dependent variable.

Neither of the respondents using a survey provided any detailed information about their instruments.

Of the preceding 16 responses, 14 were releasing their results to the public. 12 were released at no direct cost to the public, and two were released only for a direct fee. Of these 14,13 had publications accompanying their releases, and several were very elaborate.

The only respondents who offered any information on the accuracy of their measurement techniques cited 
Table 1

Overview of Survey Results

Number

Percent

Not measuring or forecasting overall local economic activity or maintaining or forecasting separate data series

Maintaining separate data series

Maintaining and forecasting separate data series

Maintaining separate data series and measuring overall local economic activity

Maintaining separate data series, measuring and forecasting overall local economic activity, forecasting separate data series

traditional tests of significance when using econometric modeling.

\section{Forecasting Local Economic Activity Results}

The information provided by the 23 respondents who were forecasting are reported in Table 3. Some of these respondents used more than one technique and, hence, totals are not related to 23 .

18 respondents were using econometric techniques, with time series models being the most prevalent reported. All of the time series respondents were using some variant of Box-Jenkins techniques. Perhaps surprisingly, no one specifically reported using vector autoregressive techniques.

A wide variety of variables was forecast. The most frequent (ten) was gross local product (income) or some proxy of it such as an index of overall local economic activity. Employment (six) and retail sales (four) were other frequently forecasted variables. Of those checking the accuracy of their forecasts, seven respondents did so by comparing the actual with the predicted. Of these, five were getting what they considered "good" accuracy, and the remainder were getting mixed results.

Of those forecasting, 15 released their forecasts to the public. 13 did so at no direct fee, and two charged a direct fee.

\section{Maintained Data Series}

The type and number of maintained data series were lengthy and varied. There were 315 different reported data series. The most frequently reported were employment data (21 percent), construction and housing data (13 percent), and financial data (11.5 percent).

\section{Foremost Problems Reported In Tracking and Forecasting Local Economic Activity}

Data collection was listed by 85 ( 80 percent) of the respondents as the foremost problem encountered. The primary problems in this area revolved around the difficulty in obtaining sufficient and necessary local data.

Statistical problems were cited by 21 respondents $(20$ percent). No one explicitly identified the problems other than five respondents who were unable to derive a measure of gross local product.

In addressing the problem of obtaining local data, the authors' experience has been that a considerable start-up cost is necessary to establish an initial data base. An initial personal contact and meeting with collecting agencies and officials has always been necessary. Additionally, an initial sorting through any available data can be extremely time consuming. Establishing an initial data base can easily

Table 2

Measuring Overall Local Economic Activity

Number

Econometric models 
Table 3

Forecasting Responses

\begin{tabular}{lc}
\hline \hline & Number \\
\hline Econometric models & 6 \\
Forecasting methodology not reported & 3 \\
Regression analysis (exact methodology not reported) & 6 \\
Simple extrapolation & 1 \\
Spectral analysis & 1 \\
Stepdown regression from state data & 1 \\
Survey instrument & 1 \\
Time series models & 7 \\
\hline \hline
\end{tabular}

require more than one year. For some, this time cost could be prohibitive.

Outside of major metropolitan areas, all desired data will most likely not be available. This problem makes the use of factor analysis to establish a coincident, and if desired, a leading, index very attractive. The same is true of the use of time series techniques for forecasting. Judgement is necessary to determine if enough of the appropriate variables are available. Once that is established, the preceding techniques will provide a usable output. The literature review that follows will provide references for carrying out these techniques.

\section{Literature Review}

This literature review will provide the reader with sources that will allow him to engage in measuring and forecasting local economic activity. It is primarily directed toward those who encounter data constraints. For this reason, the major emphasis is on index methodology for measuring and time series analysis for forecasting, where data constraints are less severe relative to those of econometric models. Given the orientation of this review toward application, some references may not be cited, and the authors apologize to those affected.

The origin of econometric models that are used to measure and forecast local activity is Glickman's (1971) model of Philadelphia. Bolton (1985) provides a very thorough review of regional econometric modeling techniques. His work covers studies of local and state models.

There are two different approaches that the index methodology has followed in measuring overall local economic activity. One is to develop an industrial production index. This methodology has been widely used by Federal Reserve district banks. The simple approach has been a value-added methodology which can be easily duplicated at any level of aggregation. The more rigorous approach uses standard econometric techniques where, normally, a theoretically correct production function is estimated. Pym (1970) provides the most commonly used methodology for the value-added approach. Hamer (1989) provides a detailed description of this approach, and his literature review includes references to the productionfunction approach. The original work of Sullivan (1975) is notable for the production-function approach. Fomby (1986) and Israilevich, Schnorbus, and Schneider (1989) compare the accuracy of the two modeling techniques. The authors' experiences have been that the value-added method was simple to construct but of limited use. Data constraints become a major factor in attempting the production-function approach.

The second approach is to develop an index as a measure of overall local economic activity and, at times, an index of leading indicators. The first rigorous attempt in this area is Bonham (1975) and his use of a diffusion index to develop leading indicators. The authors have found that a diffusion index is simple to construct but requires considerable subjective judgment to become operable and, thus, was not a desirable technique.

George (1980) provides the first rigorous and fully documented use of factor analysis to develop overall coincident and leading indicator indexes. He also provides a literature review and critique of earlier attempts at such but does not discuss the diffusion index.

Farrell and Hall (1987) and Fritz and McHone (1988), working separately, expand on George's use of factor analysis. Additionally, both add in the use of cross spectral analysis for comparing local economic cycles with those of other regions and the nation. Farrell and Hall also illustrate how to use the nation as a proxy forecaster for a local region through cross spectral relationships. Fritz and McHone introduce the use of a transfer function model to accom- 
plish this same end. Kachigan (1982) provides an easy to read description of factor analysis. Priestly (1981) provides a description of spectral analysis.

Singh $(1967,1969)$ used ordinary least squares to estimate weights for the variables in his coincident index. He converted the partial regression coefficients in his model into beta coefficients and used the latter as weights for the variables in the index.

The authors have found the factor analysis index method of measuring local economic activity and constructing leading indicators to be preferable to all others. George, Farrell and Hall, and Fritz and McHone are recommended.

For forecasting where data constraints exist, time series techniques are, perhaps, the primary alternative. One can attempt forecasts with whatever data are available, and the models are simple to construct. Their lack of adhesion to economic theory would be the primary criticism. Box and Jenkins (1976) provide the basis for what are commonly called Box-Jenkins models. For actual hands-on applications of Box-Jenkins models and spectral analysis, Brocklebank and Dickey (1986) is highly recommended. Even though this is a publication specifically directed toward the use of the Statistical Analysis System (SAS), much of the information presented is universal in nature. It is replete with examples.

Vector autoregressive models have been widely used by Federal Reserve district banks in regional forecasting. Their use in this area was originally set forth by Anderson (1979). Hoehn, Gruben, and Fomby (1984), Webb (1984) and Cargill and Morris (1988) are other useful references. As previously indicated, no respondents reported using any variation of this technique. Perhaps some of the respondents were using vector autoregressive models and did not specify such. However, because of the ease of carrying out Box-Jenkins analysis and the mixed record of improved forecast accuracy using vector autoregression relative to Box-Jenkins, this may not be surprising. Fritz (1989) provides a review and examples of relative forecast accuracy for these techniques at the regional level.

\section{Summary}

In this paper, the authors reported on the results of a survey of regional economists concerning the measurement and forecasting of local economic activity. More than half of the respondents reported that they maintained data series covering a wide variety of various types of local economic activity. Approximately 15 percent of the respondents calculated measures of overall local economic activity, and almost 22 percent made regular forecasts.

The most surprising factor was the interest expressed by 60 percent of the survey respondents to provide them with an exposure to the tools and expected problems to be encountered in this pursuit. This paper has attempted to meet this demand. It has focused on the tools that can be used where data constraints exist, which was the foremost problem cited by survey respondents.

\section{Appendix I - Survey Form}

\section{Tracking and Forecasting Local Economic Activity Survey Form}

I - Do you measure overall local economic activity? No

Yes

If Yes, please complete parts A, B and C.

A - What type of measurement instrument are you using, e.g., an index, econometric model, individual time series, etc.? If not proprietary, how is your measurement instrument constructed, and what variables are in it? (Please be specific).

B - How accurately does your instrument measure economic activity, and how do you check for this accuracy? (If you cannot answer this question, as may be the case with many, please indicate such.)

C - Is your measure of overall economic activity released to the public for its use? If so, how is it released? (E.g., local press release, local publication, etc.).

II - Do you forecast overall local economic activity?

No

Yes

If Yes, please complete parts A, B and C.

A - What do you forecast and what method(s) do you use? (Please be specific).

B - How accurate are your forecasts, and how do you check for this accuracy?

C - Are your forecasts released for public use? If so, how?

III - If you maintain data series for the local economy, please list them.

IV - What are the two foremost problems that you have encountered in tracking and forecasting overall local economic activity?

1 -

2 -

V - As we may not have found all published works in our literature review, please list the name and source of any refereed joumal articles and any books that you have published dealing with tracking and/or forecasting overall local economic activity. 


\section{References}

Anderson, P. "Help For The Regional Forecaster: Vector Autoregression." Quarterly Review. Minneapolis: Federal Reserve Bank of Minneapolis. Summer 1979. 2-7.

Bolton, R. "Regional Econometric Models." Journal of Regional Science. 25 (1985). 495-520.

Bonham, J. "A Note On A Metropolitan Area Economic Index: A Diffusion Index Approach." Joumal of Regional Science. 15 (1975). 73-80.

Box, G. and G. Jenkins. Time Series Analysis: Forecasting and Control. San Francisco: Holden-Day, 1976.

Brocklebank, J. and D. Dickey. SAS System For Forecasting Time Series. Cary, N.C.: SAS Institute, Inc., 1986.

Cargill, T. and S. Morris. "A Vector Autoregression Model of the Nevada Economy." Economic Review. San Francisco: Federal Reserve Bank of San Francisco. Winter 1988. 21-32.

Farrell, C. and W. Hall. "Tracking and Forecasting Local Economic Activity." Review of Regional Studies. 17 (1987). 31 36.

Fomby, T. "A Comparison of Forecasting Accuracies of Alternative Regional Production Index Methodologies." Journal of Business and Economic Statistics. 4 (1986). 177-186.

Fritz, R. "Forecasting Regional Housing Starts: A Comparison of Models." Unpublished paper. Federal Home Loan Bank of Atlanta, April 1989.

and W. McHone. "Forecasting Local Business Activity from Aggregate Indicators." Annals of Regional Science. 22 (1988). 63-74.

George, E. "New Economic Indicators for El Paso." Southwest
Business and Economic Review. 18 (1980). 1-44.

Glickman, N. "An Econometric Forecasting Model for the Philadelphia Region." Journal of Regional Science. 11 (1971). 15 32.

Hamer, T. "A New Regional Economic Indicator: The MidAtlantic Manufacturing Index." Business Review. Philadelphia: Federal Reserve Bank of Philadelphia. January/ February 1989. 3-14.

Hoehn, J., W. Gruben, and T. Fomby. "Time Series Forecasting Models of the Texas Economy: A Comparison." Economic Review. Dallas: Federal Reserve Bank of Dallas. May 1984. 11-23.

Israilevich, P., R. Schnorbus, and P. Schneider. "Reconsidering the Regional Manufacturing Indexes." Economic Perspectives. Chicago: Federal Reserve Bank of Chicago. July/ August 1989. 13-21.

Kachigan, S. Multivariate Statistical Analysis: A Conceptual Introduction. New York: Radius Press, 1982.

Priestly, M. Spectral Analysis and Time Series - Volume I: Univariate Series: Volume 2: Multivariate Series. Prediction and Control. New York: Academic Press, 1981.

Singh, Ajmer. "Local Business Activity Index: Its Construction and Uses." Journal of Regional Science. 7 (1967). 75-82.

"Local Business Activity Index: Its Construction and Uses - Reply." Journal of Regional Science. 9 (1969). 167 169.

Sullivan, B. Revised Methodology Of The Texas Industrial ProductionIndex. Dallas: Federal Reserve Bank of Dallas, 1975.

Webb, R. "Vector Autoregression As A Tool for Forecast Evaluation." Economic Review. Richmond: Federal ReserveBank of Richmond. (January/February 1984. 3-11. 